Research Article

\title{
Limit Drainage of Separated Tunnel Based on Ecological Groundwater Table: A Case Study
}

\author{
Jianyou Yu, ${ }^{1,2}$ Shensheng Ge, ${ }^{1,2}$ Lingchao Hou, ${ }^{1,2}$ Yiteng Zhang $\mathbb{D}^{3}{ }^{3}$ and Yuzhu Liu ${ }^{3}$ \\ ${ }^{1}$ Hebei Provincial Expressway Yanqing-Chongli Construction Office, Zhangjiakou 075000, China \\ ${ }^{2}$ Hebei Provincial Expressway Yanqing-Chongli Management Center, Zhangjiakou 075000, China \\ ${ }^{3}$ Key Laboratory of Transportation Tunnel Engineering, Ministry of Education, Southwest Jiaotong University, \\ Chengdu 610031, China \\ Correspondence should be addressed to Yiteng Zhang; zytzytlvzq@my.swjtu.edu.cn
}

Received 27 April 2021; Revised 20 August 2021; Accepted 28 August 2021; Published 14 September 2021

Academic Editor: Yu Wu

Copyright (C) 2021 Jianyou Yu et al. This is an open access article distributed under the Creative Commons Attribution License, which permits unrestricted use, distribution, and reproduction in any medium, provided the original work is properly cited.

\begin{abstract}
After the excavation of the tunnel in water-rich regions, the groundwater is continuously discharged into the tunnel. Excessive discharge will cause the groundwater table to drop, which will destroy the normal growth of vegetation and ecological balance. In order to protect the ecological environment, the key is to develop an effective method to determine the tunnel drainage. In this paper, a method for calculating the limit drainage of the tunnel is proposed based on area-well method and the concept of ecological groundwater table in ecology and agronomy. Some conclusions are drawn as follows. (1) When the ecological groundwater table is constant, with the increase of groundwater discharge, the drainage influence range of the tunnel decreases, the rainfall supplement quantity $W_{t}$ within the drainage influence range decreases, and the total groundwater discharge quantity $Q_{t}$ also decreases gradually. Since the decreasing rate of $W_{t}$ is greater than that of $Q_{t}$, there is a unit drainage that makes the total groundwater discharge equal to rainfall supplement. (2) A separated tunnel under construction in Fuzhou City is taken as an example; the limit drainage $q_{0}$ of the separated double tunnel is $0.48 \mathrm{~m}^{3} /(\mathrm{m} \cdot \mathrm{d})$ considering ecological groundwater table.
\end{abstract}

\section{Introduction}

With the development of economy and the improvement of transportation facilities in various regions, the construction of large-scale tunnels is increasing year by year, which not only brings new opportunities to the development of transportation and economic growth, but also brings challenges to the local ecological, hydrological, and geological environment [1-9]. During tunnel excavation and operation in water-rich regions, groundwater leaks through the tunnel, so the groundwater table drops $[8,10,11]$ as shown in Figure 1, leading to the reduction of surface water storage and even springs drying up. After the tunnel construction in Seoul, the annual discharge of groundwater was 63 million $\mathrm{m}^{3}$, and the groundwater table decreased from $16.85 \mathrm{~m}$ in 1996 to $20.40 \mathrm{~m}$ in 2003 [12]. The construction of a railway tunnel through the Hallandsås ridge in the southwest of Sweden resulted in drying up private wells and springs close to the tunnel axis due to groundwater drawdown [6]. The construction of Zhongliangshan tunnel in Chongqing caused 29 ground surface collapses and dried up 48 springs [13]. The influence area of surface water was about $7.2 \mathrm{~km}^{2}$, which seriously endangered the living and production water of local residents [14]. At the same time, the decrease of surface water and groundwater caused the shortage of water supply in the local ecosystem, which lead to the deterioration of plant growth. The width of tree rings in the influence area of Zhongliangshan tunnel in Chongqing continued to decrease [15], and the growth rate of dominant plants (Pinus massoniana, Cunninghamia lanceolata, etc.) declined in varying degrees due to water deficiency [16]. Tunnels excavation also decreased the soil water contents and then changed plants water uptake patterns in karst areas [17].

Such adverse effects of tunnel drainage occurred, because the waterproofing-drainage measures in the past for tunnels 


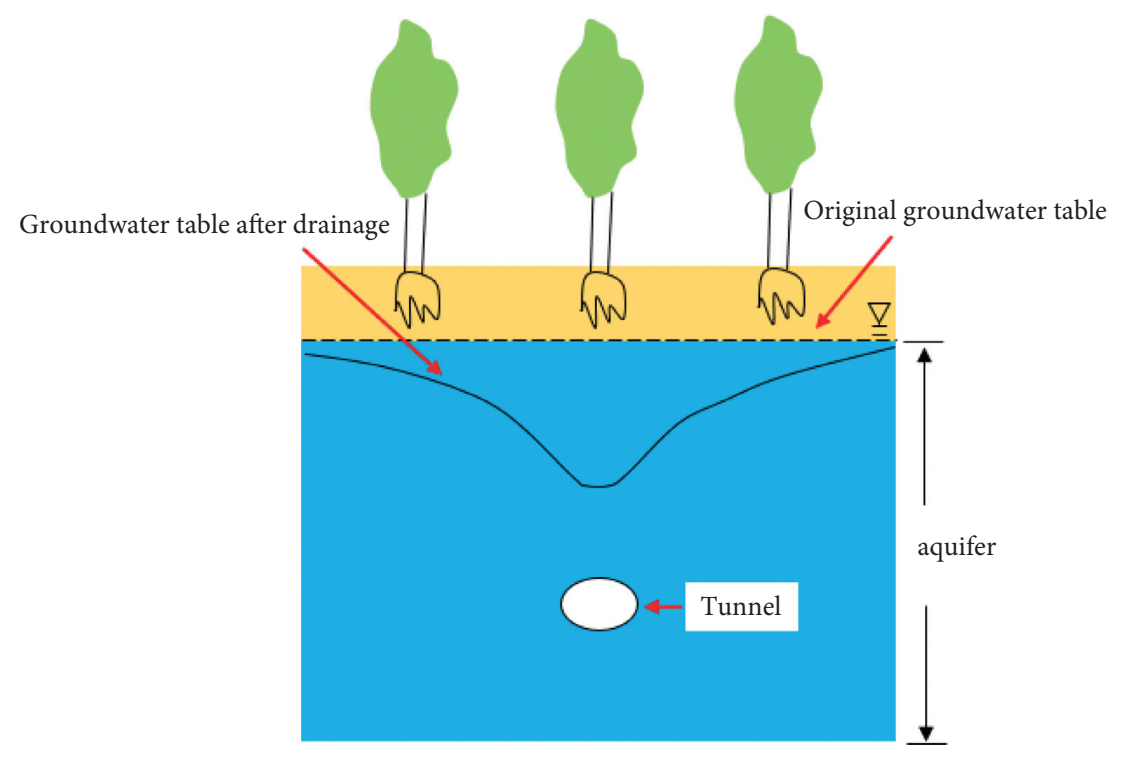

FIGURE 1: Groundwater table changes in tunnel construction.

passing through the water-rich regions were mainly free drainage to reduce the influence of water pressure on the stability of lining structure [18-20]. With the improvement of environmental protection awareness, the guiding ideology of pressure-regulated drainage has gradually been applied in engineering practice [21-23]. The principle of pressureregulated drainage is that a portion of groundwater is allowed to discharge out of the tunnel and the level of the groundwater is regulated either by a regulating value or by a raised outlet opening.

For tunnels, there have been some research on the calculation methods and standards of the groundwater drainage. For instance, the allowable drainage of Oslofjord cross-sea tunnel in Norway was determined according to the drainage capacity and economic benefits, and the maximum allowable drainage of the land section under residential and recreational areas was $0.288 \mathrm{~m}^{3} /(\mathrm{m} \cdot \mathrm{d})$ [24]. There existed ancient buildings in the upper part of Storhaug Tunnel in Norway; the water drainage range was set to $0.0432-0.144 \mathrm{~m}^{3} /(\mathrm{m} \cdot \mathrm{d})$ to protect them [25]. Due to the sensitivity of urban recreational area to groundwater drainage, the maximum allowable drainage of Baneheia Tunnel in Norway was determined to be $0.03024 \mathrm{~m}^{3} /(\mathrm{m} \cdot \mathrm{d})$ [25]. To protect the water environment and vegetation, the maximum allowable drainage of Geleshan Tunnel in China was $1.0 \mathrm{~m}^{3} /(\mathrm{m} \cdot \mathrm{d})$, and the actual drainage in operation was $0.95 \mathrm{~m}^{3} /(\mathrm{m} \cdot \mathrm{d})$, which met the design allowable drainage [26]. In order to reduce the loss of surface water around Qiyueshan Tunnel, the allowable maximum drainage was $3.0 \mathrm{~m}^{3} /(\mathrm{m} \cdot \mathrm{d})$, which was determined based on the engineering geological conditions, hydrological conditions, and the drainage capacity of equipment [22]. Based on the ecological water demand of vegetation, [27] studied the drainage funnel after tunnel drainage and obtained the calculation method for tunnel drainage to maintain the ecological balance of vegetation and groundwater.

At present, the study of groundwater in coal mining is more mature, proposing water inrush solution measures
[28] and giving the protection of aquifers [29]. However, there is no relatively unified calculation method of tunnel drainage and the limit standard with wider applicability; the previous provisions of tunnel drainage have their own considerations and specific provisions in terms of the use function and geological environment. In this research, from the perspective of vegetation demand and drawing on the area-well method in groundwater dynamics, the relationship between the groundwater drawdown and the time, and drainage quantity of the tunnel are obtained. Then through the balance analysis of the total groundwater discharge $Q_{t}$ and the total groundwater supply $W_{t}$ mainly from rainfall infiltration supply, the method for calculating the drainage to maintain the balance of groundwater is proposed. Finally, taking a separated double-hole tunnel under construction in Fuzhou as an example, its limit drainage is determined.

\section{Relationship between Groundwater Table and Vegetation}

Groundwater provides plants with water, salt, organic nutrients, and heat. When the groundwater table drops enough, the root system cannot absorb enough water from the capillary zone, leading to vegetation degradation. If water is in short supply for a long time, vegetation will disappear. When the groundwater table is enough shallow, it may cause soil salinization and threaten the growth of vegetation. According to this phenomenon, the concept of ecological groundwater table is put forward, which means that the groundwater table meets the normal growth of plants and the problems of vegetation degradation, land desertification, and soil salinization will not occur under no irrigation [30].

Yang et al. [31] used the Yushen coal mine district in $\mathrm{Mu}$ Us Desert to study quantitative analysis of the relationship between vegetation and groundwater table in different ecological and geological (ecogeological) environments. Liu 
et al. [32] used the Yushenfu mining area as a case study; the ecosafety groundwater table was determined to be $1.5 \sim 5.0 \mathrm{~m}$ based on the curve describing the relationship between groundwater table and NDVI (the Normalized Difference Vegetation Index, as obtained by optical satellites, is one of the most popular indicators for the status of vegetation). Horton et al. [33] analyzed the physiological response of three different plants to the change of groundwater table and proposed the range of groundwater table to maintain the normal growth of two plants. Newman et al. [34] summarized the research results of many scholars and proposed the relationship between groundwater and vegetation growth from the perspective of ecology hydrology. Shi et al. [35] studied the relationship between groundwater and vegetation based on vegetation coverage and proposed the groundwater table suitable for different vegetation growth in different regions. Cheng et al. [36] analyzed the relationship between different plant populations, plant coverage, and groundwater table, pointed out that the groundwater table and soil moisture content in aeration zone were important factors affecting vegetation growth, and proposed the groundwater table suitable for different vegetation.

The above analysis shows that vegetation is closely related to groundwater table. Therefore, when determining the tunnel drainage, it is necessary to introduce the ecological groundwater table. Groundwater drawdown caused by tunnel drainage must be ensured not exceeding the ecological groundwater table to protect the vegetation of the tunnel site.

\section{Theoretic Methods for Calculating Tunnel Drainage}

Based on the ecological groundwater table, the specific progress of the theoretical method for calculating tunnel drainage is shown in Figure 2. First, based on area-well method in groundwater dynamics, the groundwater seepage model of a single-hole tunnel and separated tunnel is established, which reveals this relationship between the water inflow quantity and groundwater table drawdown. Second, according to the proposed groundwater seepage model, the influence range of groundwater drainage funnel is derived under the premise of controlling the maximum groundwater drawdown within the range required by normal growth of vegetation. Then the rainfall supplement quantity $W_{t}$ within the influence range is obtained by using the method of rainfall infiltration coefficient, and then $W_{t}$ is compared to the total groundwater discharge quantity $Q_{t}$. Through adjusting groundwater discharge $q_{0}$ to make $W_{t}$ equal to $Q_{t}, q_{0}$ is the maximum allowable groundwater discharge in the tunnel site.

\subsection{Relationship between Tunnel Drainage and Groundwater Drawdown}

3.1.1. The Groundwater Drawdown under the Drainage of the Single-Hole Tunnel. Due to the similarity between tunnel seepage and well pumping, the current calculation method for groundwater drawdown after tunnel drainage is generally based on well flow theory in groundwater dynamics. In the well flow theory, the assumption is that (1) the well diameter is infinitely small; (2) the well is vertical; and (3) the drawdown occurs around the wellhead. While the tunnel is equivalent to the horizontal well, the drawdown funnel will appear at the top of the tunnel. Therefore, it can be assumed that the tunnel wall is composed of infinite pumping wells, and the superposition of infinite pumping wells is considered as shown in Figure 3 [14].

For the superposition of infinite pumping wells, the areawell method is adopted to obtain the final groundwater drawdown. The area-well method is that when the flow distribution of a well hole is relatively uniform on a certain geometric shape (such as rectangle and circle), the well group can be regarded as a whole, and the pumping from each well is regarded as the uniform "evaporation" on the distribution area of the well group [37].

If the area-well method is adopted for determining tunnel drainage, the following assumptions should be made: (1) the tunnel cross section is assumed to be standard circular, and the tunnel as a whole is cylindrical. However, the shape of the tunnel cross section is usually horseshoe-shaped and needs to be converted into a circle by area equivalence principle. (2) The water inflow on the tunnel wall is uniform, stable, and equal everywhere.

The length of the tunnel is $L$ and the radius is $R_{0}$, as shown in Figure 4(a). When the tunnel wall surface is expanded into a plane, the plane size is $L=2 l_{x}$ and the width is $2 \pi R_{0}=2 l_{y}$, as shown in Figure 4(b) [27]. Assuming that the plane is composed of numerous tiny seepage surfaces, the water inflow on the plane is equal everywhere. The action of microelement on any point $M$ can be regarded as the action of a single well, so the action of the whole face to the point $M$ can be obtained by integrating the action of microelement.

Assuming that the daily water inflow per linear meter of a tunnel is $q$, the total water inflow per unit time on the seepage surface can be expressed by

$$
Q=q L,
$$

where $Q$ is the daily tunnel water inflow $\left(\mathrm{m}^{3} / \mathrm{d}\right) ; q$ is the daily water inflow per linear meter of a tunnel $\left(\mathrm{m}^{3} \cdot \mathrm{d}^{-1} \mathrm{~m}^{-1}\right) ; L$ is the length of the tunnel $(\mathrm{m})$.

Therefore, water inflow per unit area can be expressed by

$$
\varepsilon=\frac{Q}{2 l_{x} \cdot 2 l_{y}}=\frac{q L}{2 l_{x} \cdot 2 l_{y}},
$$

where $\varepsilon$ is the water inflow per unit area $(\mathrm{m} / \mathrm{d})$.

The coordinate system is taken as shown in Figure 4(b). The $x^{\prime} o y^{\prime}$ coordinate system represents the position of the microelement, and the xoy coordinate system represents the position of calculation point for drawdown.

Because it takes a long time for the groundwater around the tunnel to form a stable flow state, the calculation method of unsteady groundwater flow fits the actual situation better. Theis well function [38] is the most widely used formula involving the unsteady flow of groundwater, as expressed by

$$
s=\frac{Q}{4 \pi T} W(u)
$$




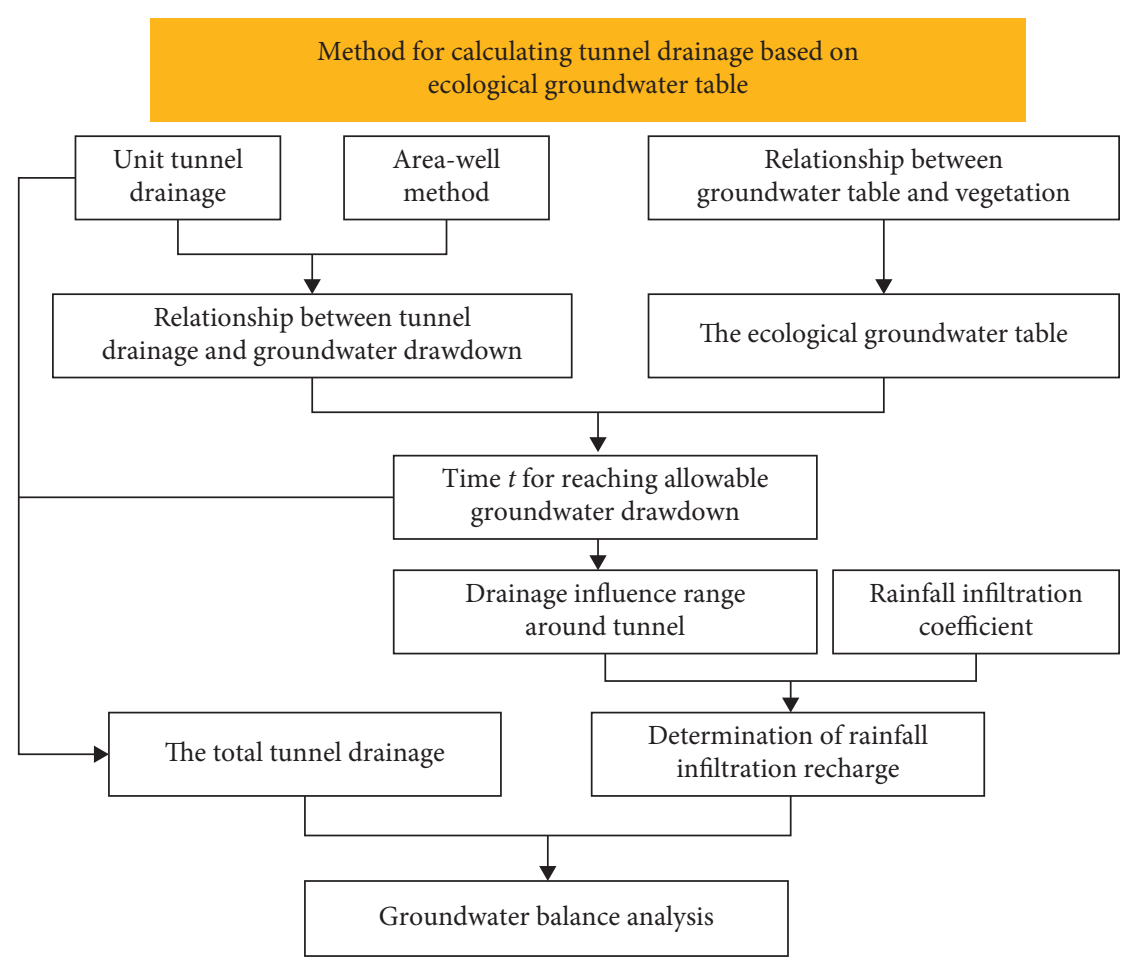

FIgure 2: The specific progress of the theoretical method for calculating tunnel drainage.

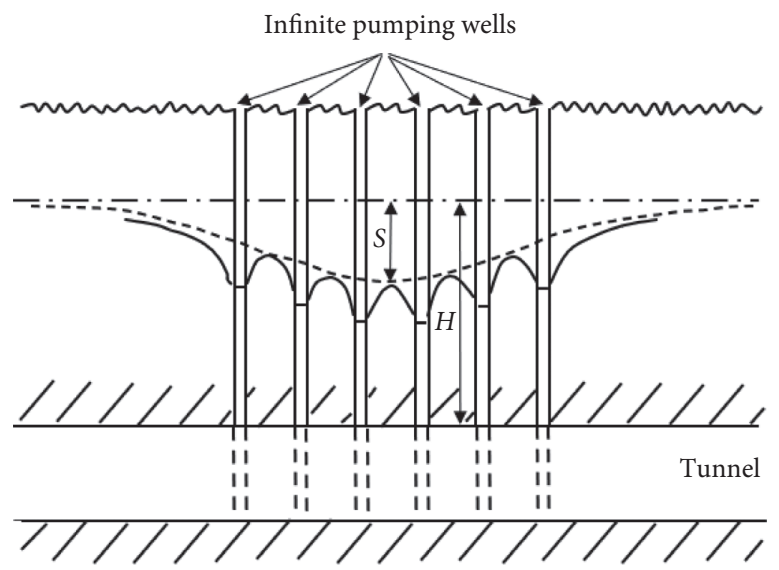

FIgURE 3: Schematic diagram of pumping wells in the longitudinal section of the tunnel.

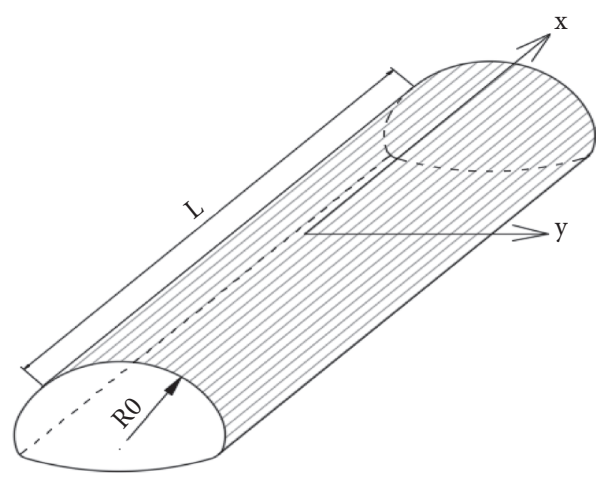

(a)

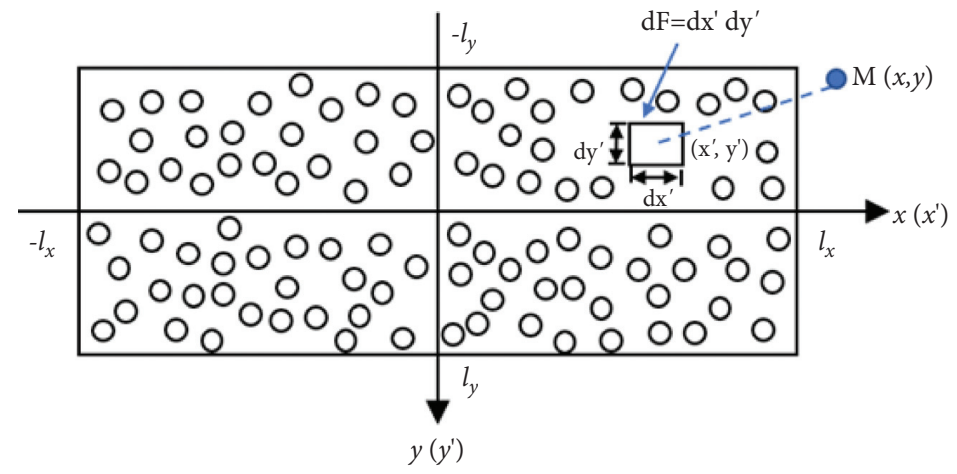

(b)

Figure 4: (a) The profile of single-hole tunnel and (b) schematic diagram of area wells. 
And the dimensionless parameter $u$ is defined by

$$
u=\frac{r^{2} \mu}{4 T t}
$$

The well function is defined by

$$
W(u)=\int_{r^{2} / 4 a t}^{\infty} \frac{e^{-x}}{x} d_{x},
$$

where $s$ is the groundwater drawdown $(\mathrm{m}) ; \mathrm{Q}$ is the daily tunnel water inflow $\left(\mathrm{m}^{3} / \mathrm{d}\right)$; $T$ is the transmissibility coefficient $\left(\mathrm{m}^{2} / \mathrm{d}\right) ; a$ is the coefficient of pressure conductivity, where $a=T / \mu$, and $\mu$ is the specific yield; $t$ is time from the start of leakage $(d) ; r$ is the distance between the groundwater drawdown point and the well $(\mathrm{m})$.

The mathematical substitution of Theis well function is carried out. Setting

$$
x=\frac{r^{2}}{4 a \xi} .
$$

Then we get the differential of $x$ as expressed by

$$
\mathrm{d}_{x}=\frac{r^{2}}{4 a} \frac{-\mathrm{d} \xi}{\xi^{2}}=-x \frac{\mathrm{d} \xi}{\xi} .
$$

Thus, equation (5) can be expressed by

$$
\int_{r^{2} / 4 a t}^{\infty} \frac{e^{-x}}{x} \mathrm{~d}_{x}=-\int_{t}^{0} \frac{e^{-\left(r^{2} / 4 a \xi\right)}}{x} \cdot x \frac{\mathrm{d} \xi}{\xi}=\int_{0}^{t} \frac{e^{-\left(\left(r^{2} / 4 a \xi\right)\right)}}{\xi} \mathrm{d} \xi .
$$

Then, equation (8) (the well function after substitution) is brought into equation (3), and the drawdown at any point can be expressed by

$$
s=\frac{Q}{4 \pi T} \int_{0}^{t} \frac{e^{\left(r^{2} / 4 a \xi\right)}}{\xi} \mathrm{d} \xi .
$$

Assuming that there is any point $M(x, y)$ in the tunnel area, the drawdown under the action of seepage surface with discharge $Q$ is solved by the following method.

Taking any point $\left(x^{\prime}, y^{\prime}\right)$ as the center and getting microelement $\mathrm{d} x^{\prime} \mathrm{d} y^{\prime}$ on the seepage surface, the water flow of the microelement is $\varepsilon \mathrm{d} x^{\prime} \mathrm{d} y^{\prime}$. Point $M(x, y)$ under the seepage action of differential surface $\mathrm{d} x^{\prime} \mathrm{d} y^{\prime}$, its differential drawdown ds can be expressed by the following equation based on equation (9):

$$
\begin{aligned}
\mathrm{d} s & =\frac{\varepsilon \mathrm{d} x^{\prime} \mathrm{d} y x^{\prime}}{4 \pi T} \int_{0}^{t} \frac{e^{\left(-\left(x-x^{\prime}\right)^{2}+\left(y-y^{\prime}\right)^{2} / 4 a \xi\right)}}{\xi} \mathrm{d} \xi \\
& =\frac{\varepsilon \mathrm{d} x x^{\prime} \mathrm{d} y x^{\prime}}{4 \pi T} \int_{0}^{t} \frac{e^{\left(-\left(x-x^{\prime}\right)^{2} / 4 a \xi\right)}}{\sqrt{\xi}} \cdot \frac{e^{\left(-\left(y-y^{\prime}\right)^{2} / 4 a \xi\right)}}{\sqrt{\xi}} \mathrm{d} \xi .
\end{aligned}
$$

The drawdown of point $M(x, y)$ under the action of seepage face can be obtained by integrating in the whole face, as expressed by

$$
\begin{gathered}
s=\frac{\varepsilon}{4 T} \int_{0}^{t}\left[\frac{1}{\sqrt{\pi}} \int_{-l_{x}}^{l_{x}} \frac{e^{\left(-\left(x-x^{\prime}\right)^{2} / 4 a \xi\right)}}{\sqrt{\xi}} \mathrm{d} x^{\prime}\right. \\
\left.\cdot \frac{1}{\sqrt{\pi}} \int_{-l_{x}}^{l_{x}} \frac{e^{-\left(y-y^{\prime}\right)^{2} / 4 a \xi}}{\sqrt{\xi}} \mathrm{d} y^{\prime} \cdot\right] \mathrm{d} \xi .
\end{gathered}
$$

The mathematical substitution of equation (11) is carried out. Setting

$$
\eta^{2}=\frac{\left(x-x^{\prime}\right)^{2}}{4 a \xi}
$$

Then we get the differential of $\eta$ as expressed by

$$
\mathrm{d} \eta=\frac{-\mathrm{d} x^{\prime}}{\sqrt{4 a \xi}}
$$

Therefore, the following equation can be obtained:

$$
\begin{aligned}
\frac{1}{\sqrt{\pi}} \int_{-l_{x}}^{l_{x}} \frac{e^{-\left(x-x^{\prime}\right)^{2} / 4 a \xi}}{\sqrt{\xi}} \mathrm{d} x^{\prime} & =\frac{-1}{\sqrt{\pi}} \int_{x+l_{x} / \sqrt{4 a \xi}}^{x-l_{x} / \sqrt{4 a \xi}} \frac{e^{-\eta^{2}}}{\sqrt{\xi}} \cdot \sqrt{4 a \xi} \mathrm{d} n \\
& =\frac{2}{\sqrt{\pi}} \sqrt{a} \int_{x+l_{x} / \sqrt{4 a \xi}}^{x-l_{x} / \sqrt{4 a \xi}} e^{-\eta^{2}} \mathrm{~d} n \\
& =\sqrt{a}\left[\operatorname{erf}\left(\frac{x+l_{x}}{\sqrt{4 a \xi}}\right)-\operatorname{erf}\left(\frac{x-l_{x}}{\sqrt{4 a \xi}}\right)\right]
\end{aligned}
$$

where $\operatorname{erf}(v)=(2 / \sqrt{\pi}) \int_{0}^{v} e^{-x^{2}} \mathrm{~d} x$ is called Gaussian error function.

In the same way, equation (15) can be obtained as follows:

$$
\begin{aligned}
& \frac{1}{\sqrt{\pi}} \int_{-l_{y}}^{l_{y}} \frac{e^{\left(-\left(y-y^{\prime}\right)^{2} / 4 a \xi\right)}}{\sqrt{\xi}} \mathrm{d} y^{\prime} \\
& \quad=\sqrt{a}\left[\operatorname{erf}\left(\frac{y+l_{y}}{\sqrt{4 a \xi}}\right)-\operatorname{erf}\left(\frac{y-l_{y}}{\sqrt{4 a \xi}}\right)\right] .
\end{aligned}
$$

Substituting equations (14) and (15) into equation (11) and noticing that $T=a \mu$, equation (16) can be obtained as follows:

$$
\begin{aligned}
s= & \frac{\varepsilon}{4 u} \int_{0}^{t}\left[\operatorname{erf}\left(\frac{x+l_{x}}{4 a \xi}\right)-\operatorname{erf}\left(\frac{x-l_{x}}{4 a \xi}\right)\right] \\
& \times\left[\operatorname{erf}\left(\frac{y+l_{y}}{4 a \xi}\right)-\operatorname{erf}\left(\frac{y-l_{y}}{4 a \xi}\right)\right] \mathrm{d} \xi .
\end{aligned}
$$

The mathematical substitution of equation (16) is carried out. Setting $\tau=\xi / t$, then we get the differential $\mathrm{d} \tau=\mathrm{d} \xi / t$, and equation (16) is converted into 


$$
\begin{aligned}
s= & \frac{\varepsilon}{4 u} \int_{0}^{1}\left[\operatorname{erf}\left(\frac{x+l_{x}}{\sqrt{4 a t \tau}}\right)-\operatorname{erf}\left(\frac{x-l_{x}}{\sqrt{4 a t \tau}}\right)\right] \times\left[\operatorname{erf}\left(\frac{y+l_{y}}{\sqrt{4 a t \tau}}\right)-\operatorname{erf}\left(\frac{y-l_{y}}{\sqrt{4 a t \tau}}\right)\right] t d \tau \\
= & \frac{\operatorname{ct}}{4 u}\left[\int_{0}^{1} \operatorname{erf}\left(\frac{x+l_{x}}{\sqrt{4 a t \tau}}\right) \operatorname{erf}\left(\frac{y+l_{y}}{\sqrt{4 a t \tau}}\right) \mathrm{d} \tau+\int_{0}^{1} \operatorname{erf}\left(\frac{x+l_{x}}{\sqrt{4 a t \tau}}\right) \operatorname{erf}\left(\frac{l_{y}-y}{\sqrt{4 a t \tau}}\right) \mathrm{d} \tau+\int_{0}^{1} \operatorname{erf}\left(\frac{l_{x}-x}{\sqrt{4 a t \tau}}\right) \operatorname{erf}\left(\frac{l_{y}+y}{\sqrt{4 a t \tau}}\right) \mathrm{d} \tau\right. \\
& \left.+\int_{0}^{1} \operatorname{erf}\left(\frac{l_{x}-x}{\sqrt{4 a t \tau}}\right) \operatorname{erf}\left(\frac{l_{y}-y}{\sqrt{4 a t \tau}}\right) \mathrm{d} \tau\right] .
\end{aligned}
$$

Define the following function:

$$
S^{*}(\alpha, \beta)=\int_{0}^{1} \operatorname{erf}\left(\frac{\alpha}{\sqrt{\tau}}\right) \operatorname{erf}\left(\frac{\beta}{\sqrt{\tau}}\right) \mathrm{d} \tau .
$$

Then, the drawdown at any point $M(x, y)$ under the action of rectangular area well can be expressed by

$$
s=\frac{\varepsilon t}{4 u} A_{r}\left(l_{x}, l_{y}, x, y, a t\right)
$$

Here, $A_{r}$ is expressed by

$$
\begin{aligned}
A_{r}(l x, l y, x, y, a t)= & S^{*}\left(\frac{x+l_{x}}{\sqrt{4 a t}}, \frac{y+l_{y}}{\sqrt{4 a t}}\right)+S^{*}\left(\frac{x+l_{x}}{\sqrt{4 a t}}, \frac{l_{y}-y}{\sqrt{4 a t}}\right) \\
& +S^{*}\left(\frac{l_{x}-x}{\sqrt{4 a t}}, \frac{l_{y}+y}{\sqrt{4 a t}}\right) \\
& +S^{*}\left(\frac{l_{x}-x}{\sqrt{4 a t}}, \frac{l_{y}-y}{\sqrt{4 a t}}\right),
\end{aligned}
$$

where $A_{r}$ can be called the well function of rectangular area well. In this paper, a program for calculating $S^{*}(\alpha, \beta)$ value in any of the scopes of $\alpha$ and $\beta$ is developed based on MATLAB. For the center point of a single-hole tunnel, setting $x=0$ and $y=0$ in equation (19), the groundwater drawdown of the tunnel center point can be expressed by

$$
s_{c}=\frac{\varepsilon t}{\mu} S^{*}\left(\frac{l_{x}}{\sqrt{4 a t}}, \frac{l_{y}}{\sqrt{4 a t}}\right),
$$

where $s_{c}$ is the groundwater drawdown of the tunnel center point.

Obviously, the maximum groundwater drawdown is at the center of the tunnel, so equation (21) is the calculation formula of the maximum groundwater table drawdown caused by tunnel drainage. $s_{c}$ is a function of $t$, which can be calculated when $s_{c}$ and tunnel water inflow $q$ are given.

\subsubsection{The Groundwater Drawdown under the Drainage of the} Separated Double-Hole Tunnel. For the separated doublehole tunnel (Figure 5(a)), the area-well method is also adopted, and the two tunnels are equivalent to two area wells, as shown in Figure 5(b).

For a single-hole tunnel, the drawdown equation of any point $M(x, y)$ under the action of rectangular area wells is expressed by equations (1), (2), (19), and (20). For separated tunnels, the drawdown of point $M$ is the sum of the drawdown caused by the drainage of left tunnel and right tunnel, as shown in Figure 5(b). Setting the drainage quantity of the left tunnel as $q_{1}$, the drainage quantity of the right tunnel is $q_{2}$. The diameter, length, and width of the left tunnel and right tunnel are the same, and they are $r, L$, and $B$, respectively. The distance between the left and right tunnel is $D$, and the coordinate origin is set in the center of the left tunnel, as shown in Figure 5(b). According to equations (1), (2), (19), and (20), the drawdown $s_{1}$ due to drainage in left tunnel to point $M$ is expressed by

$$
\begin{aligned}
Q_{1}= & q_{1} L, \\
\varepsilon_{1}= & \frac{Q_{1}}{2 l_{x}} \cdot 2 l_{y} . \\
s_{1}= & \frac{\varepsilon_{1} t}{4 \mu}\left[S^{*}\left(\frac{L / 2+x}{\sqrt{4 a t}}, \frac{B / 2+y}{\sqrt{4 a t}}\right)+S^{*}\left(\frac{L / 2+x}{\sqrt{4 a t}}, \frac{B / 2-y}{\sqrt{4 a t}}\right)\right. \\
& \left.+S^{*}\left(\frac{L / 2-x}{\sqrt{4 a t}}, \frac{B / 2+y}{\sqrt{4 a t}}\right)+S^{*}\left(\frac{L / 2-x}{\sqrt{4 a t}}, \frac{B / 2-y}{\sqrt{4 a t}}\right)\right] .
\end{aligned}
$$

For the left tunnel, the right tunnel is equivalent to a right translation $(D+B)$ along the $y$-coordinate direction. Therefore, the drawdown $s_{2}$ due to seepage in right tunnel to point $M$ is expressed by

$$
\begin{aligned}
Q_{2}= & q_{2} L, \\
\varepsilon_{2}= & \frac{Q_{2}}{2 l_{x}} \cdot 2 l_{y}, \\
s_{2}= & \frac{\varepsilon_{2} t}{4 \mu}\left[S^{*}\left(\frac{L / 2+x}{\sqrt{4 a t}}, \frac{B / 2+y-D-B}{\sqrt{4 a t}}\right)\right. \\
& +S^{*}\left(\frac{L / 2+x}{\sqrt{4 a t}}, \frac{B / 2-y+D+B}{\sqrt{4 a t}}\right) \\
& +S^{*}\left(\frac{L / 2-x}{\sqrt{4 a t}}, \frac{B / 2+y-D-B}{\sqrt{4 a t}}\right) \\
& \left.+S^{*}\left(\frac{L / 2-x}{\sqrt{4 a t}}, \frac{B / 2-y+D+B}{\sqrt{4 a t}}\right)\right] .
\end{aligned}
$$

For the drawdown $s$ of $M$ point, $s=s_{1}+s_{2}$ is formed by superposition of the drawdown of the left tunnel and right tunnel. Except that $x$ and $y$ are independent variables and other parameters in $s$ function are constants, the maximum value of $s$ appears in the center of the left tunnel and the right 


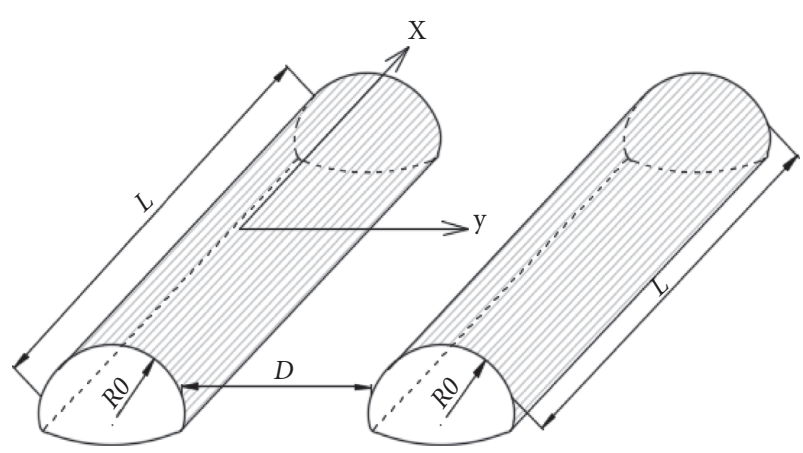

(a)

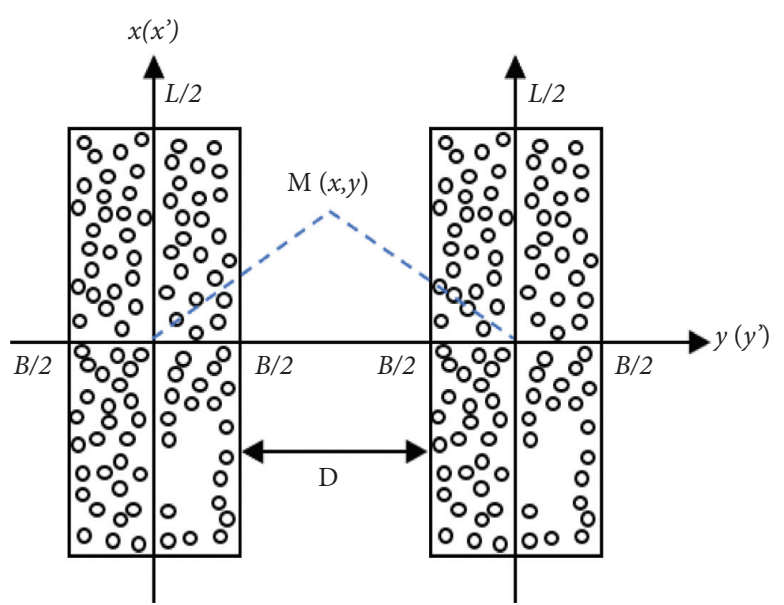

(b)

FIgURE 5: (a) The profile of double-hole tunnel. (b) Schematic diagram of area wells considering the influence of two tunnels.

tunnel through mathematical means. Therefore, the center drawdown of any tunnel is selected as the groundwater control drawdown. Setting that the drawdown at the center of the left tunnel is the control drawdown, when $x=0$ and $y=0$, the drawdown at the center of the left tunnel can be expressed by

$$
s_{l}=\frac{\varepsilon_{1} t}{\mu} S^{*}\left(\frac{L / 2}{\sqrt{4 a t}}, \frac{B / 2}{\sqrt{4 a t}}\right)
$$

where $s_{l}$ is the groundwater drawdown at the center of the left tunnel due to left tunnel seepage.

Similarly, the drawdown at the center of the left tunnel due to right tunnel seepage can be expressed by

$s_{r}=\frac{\varepsilon_{2} t}{2 \mu}\left[S^{*}\left(\frac{L / 2}{\sqrt{4 a t}}, \frac{B / 2-D-B}{\sqrt{4 a t}}\right)+S^{*}\left(\frac{L / 2}{\sqrt{4 a t}}, \frac{B / 2+D+B}{\sqrt{4 a t}}\right)\right]$,

where $s_{r}$ is the groundwater drawdown at the center of the left tunnel due to right tunnel seepage.

If the maximum allowable drawdown $s$ is given, the time $t$ to reach the maximum drawdown can be obtained by equations (28) and (29).

\subsection{Drainage Influence Range around Tunnel}

3.2.1. Horizontal Influence Range. For the tunnel sites without obvious recharge boundary and watershed, a place with groundwater drawdown of approximately $0 \mathrm{~m}$ is the boundary of the influence range. Pumping over time creates a pumping funnel around the well. Depending on the flow characteristics of the well, a descending funnel will form above the tunnel when the discharge is too high. However, unlike a well, the length of the tunnel is much greater than the width; therefore, the shape of the pumping funnel is an inverted elliptical cone. The elliptical scope of the drawdown funnel is the influence scope of the tunnel and the rainfall infiltration recharge area [27], as shown in Figure 6.

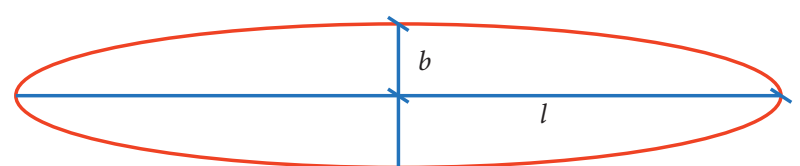

Figure 6: Influence range of tunnel drainage funnel.

The drawdown of each point is the superposition of double tunnels; then, the influence range in the middle of the tunnel is the largest in transverse direction. The coordinate of the horizontal groundwater drawdown of approximately $0 \mathrm{~m}$ is taken as the ellipse short radius $b$ in the influence range.

Taking the center point of the left tunnel as the origin, the coordinate system is shown in Figure 5(b). Then, the expression of drawdown at any point is the sum of the left tunnel's drawdown $s_{h 1}$ and the right tunnel's drawdown $s_{h 2}$. Setting $x=0$ and $y=-b$ in equation (24), groundwater drawdown $s_{h 1}$ at transverse $-b$ in the middle of the tunnel caused by the left tunnel's seepage can be expressed by

$$
s_{h 1}=\frac{\varepsilon_{1} t}{2 \mu}\left[S^{*}\left(\frac{L / 2}{\sqrt{4 a t}}, \frac{B / 2+b}{\sqrt{4 a t}}\right)+S^{*}\left(\frac{L / 2}{\sqrt{4 a t}}, \frac{B / 2-b}{\sqrt{4 a t}}\right)\right] .
$$

Setting $x=0$ and $y=-b$ in equation (27), groundwater drawdown $s_{h 2}$ at transverse $-b$ in the middle of the tunnel caused by the right tunnel's seepage can be expressed by

$$
\begin{aligned}
s_{h 2}= & \frac{\varepsilon_{2} t}{2 \mu}\left[S^{*}\left(\frac{L / 2}{\sqrt{4 a t}}, \frac{B / 2-D-B-b}{\sqrt{4 a t}}\right)\right. \\
& \left.+S^{*}\left(\frac{L / 2}{\sqrt{4 a t}}, \frac{B / 2+D+B+b}{\sqrt{4 a t}}\right)\right] .
\end{aligned}
$$

After considering the superposition of two tunnels, the groundwater drawdown at $y=-b$ in the middle of the tunnel can be expressed by 


$$
s_{h}=s_{h 1}+s_{h 2} .
$$

When $s_{h}=0$, the $b$ is obtained, which is the ellipse short radius in the influence range of the tunnel.

3.2.2. Longitudinal Influence Range. In the longitudinal direction, considering the symmetry of the left tunnel and the right tunnel, the groundwater drawdown on the center line of the left tunnel and the right tunnel is the same. Therefore, a place with drawdown of approximately $0 \mathrm{~m}$ in the direction of $x$ axis is taken as the ellipse long radius $l$ in the influence range.

Setting $x=l$ and $y=0$ in equation (24), groundwater drawdown $s_{z 1}$ at longitudinal $l$ caused by the left tunnel's seepage can be expressed by

$$
s_{z 1}=\frac{\varepsilon_{1} t}{2 \mu}\left[S^{*}\left(\frac{L / 2+l}{\sqrt{4 a t}}, \frac{B / 2}{\sqrt{4 a t}}\right)+S^{*}\left(\frac{L / 2-l}{\sqrt{4 a t}}, \frac{B / 2}{\sqrt{4 a t}}\right)\right] .
$$

Setting $x=l$ and $y=0$ in equation (27), groundwater drawdown $s_{z 1}$ at longitudinal $l$ caused by the right tunnel's seepage can be expressed by

$$
\begin{aligned}
s_{z 2}= & \frac{\varepsilon_{2} t}{4 \mu}\left[S^{*}\left(\frac{L / 2+l}{\sqrt{4 a t}}, \frac{B / 2-D-B}{\sqrt{4 a t}}\right)\right. \\
& +S^{*}\left(\frac{L / 2+l}{\sqrt{4 a t}}, \frac{B / 2+D+B}{\sqrt{4 a t}}\right) \\
& +S^{*}\left(\frac{L / 2-l}{\sqrt{4 a t}}, \frac{B / 2-D-B}{\sqrt{4 a t}}\right) \\
& \left.+S^{*}\left(\frac{L / 2-l}{\sqrt{4 a t}}, \frac{B / 2+D+B}{\sqrt{4 a t}}\right)\right] .
\end{aligned}
$$

After considering the superposition of double tunnels, the groundwater drawdown at $x=l$ can be expressed by

$$
s_{z}=s_{z 1}+s_{z 2} \text {. }
$$

When $s_{z}=0$, the $l$ is obtained, which is the ellipse long radius in the influence range.

3.2.3. Influence Range of Tunnel Seepage Funnel. After the short radius and long radius of the ellipse are respectively determined by equations (32) and (35), the influence range of the tunnel drainage funnel can be determined, as shown in Figure 6. Accordingly, the ellipse area $F$ can be obtained, as expressed by equation (36). $\mathrm{F}$ is also the rainfall infiltration recharge area:

$$
F=\pi l b .
$$

3.3. Determination of Rainfall Infiltration Recharge. For tunnel engineering, rainfall infiltration is usually the main recharge source of groundwater. The general process of rainfall infiltration is that rainwater first replenishes water in the vadose zone above the groundwater surface, and when the water content in the vadose zone reaches the field water capacity, rainwater will be replenishment to the groundwater. In order to accurately understand the recharge of rainfall to groundwater, rainfall infiltration coefficient is an important evaluation parameter. Rainfall infiltration coefficient is the ratio of rainfall infiltration supplement $W_{r}$ to the corresponding precipitation $W$; that is, $p=W_{r} / W$ [39].

In plain, hill, and mountain areas, when there is no test data, the precipitation infiltration coefficient of aquifer can be approximately determined according to Table 1 [40].

Rainfall can be obtained according to local meteorological statistics. According to the area, annual rainfall and infiltration coefficient are obtained in the recharge regions, and the amount of daily recharge within the influence scope can be obtained, as expressed by [39]

$$
W_{r}=\frac{p W F}{365}
$$

where $W_{r}$ is the daily average rainfall infiltration supply $\left(\mathrm{m}^{3} /\right.$ d); $p$ is rainfall infiltration coefficient; $W$ is annual rainfall; $F$ is the area replenished by rainfall infiltration $\left(\mathrm{m}^{3}\right)$.

3.4. Groundwater Balance Analysis. In the process of groundwater drawdown calculation, the water inflow per unit time is $q$; then, the total water inflow in time $t$ can be expressed by

$$
Q_{t}=q L t
$$

The total supply of precipitation in time $t$ can be expressed by

$$
W_{t}=W_{r} t
$$

After reaching allowable drawdown, the total amount of drainage $Q_{t}$ and the amount of recharge $W_{t}$ are obtained. (1) If $Q_{t}=W_{t}$, the groundwater is just in balance, and the groundwater table will no longer continue to decline. (2) If $Q_{t}>W_{t}$, the drainage is too large. In this case, the groundwater will be drained and the ecological environment will be affected. Therefore, water inflow should be reduced to balance the discharge and supply. (3) If $Q_{t}<W_{t}$, the discharge is appropriate, and no action is required.

\section{Case Study}

4.1. Tunnel Description. The proposed tunnel is a separated double-hole tunnel with an average distance of about $20 \mathrm{~m}$. The total length of the left and right lines is 1176 and $1140 \mathrm{~m}$, respectively, and about $1000 \mathrm{~m}$ of them pass through the aquifer. The tunnel has a width of $20.02 \mathrm{~m}$, a height of $13.53 \mathrm{~m}$, and an equivalent circle radius of $10.8 \mathrm{~m}$. The main surrounding rock of the tunnel site is unstable completely weathered granite and moderately weathered granite. The average thickness of the underground aquifer is $H=30 \mathrm{~m}$. The permeability coefficient of the surrounding rock is taken from the geotechnical engineering investigation report of the detailed investigation stage of the extension line project of North Industrial Road (section I) in Fuzhou City [41]. The 
TABLE 1: Infiltration coefficient of precipitation in different strata.

\begin{tabular}{lc}
\hline Strata & Infiltration coefficient $p$ \\
\hline Silty clay & $0.01 \sim 0.02$ \\
Silt & $0.02 \sim 0.05$ \\
Mealy sand & $0.05 \sim 0.08$ \\
Fine sand & $0.08 \sim 0.12$ \\
Medium sand & $0.12 \sim 0.18$ \\
Coarse sand & $0.18 \sim 0.24$ \\
Round gravel (sand inclusion) & $0.24 \sim 0.30$ \\
Pebble (sand inclusion) & $0.30 \sim 0.35$ \\
Intact rock & $0.01 \sim 0.10$ \\
Relatively intact rock & $0.10 \sim 0.15$ \\
Relatively broken rock & $0.15 \sim 0.18$ \\
Broken rock & $0.18 \sim 0.20$ \\
Extremely broken rock & $0.20 \sim 0.25$ \\
Very weak karst development & $0.01 \sim 0.10$ \\
Weak karst development & $0.10 \sim 0.15$ \\
Karst medium development & $0.15 \sim 0.20$ \\
Karst development & $0.20 \sim 0.50$ \\
\hline
\end{tabular}

comprehensive value of the permeability coefficient in this paper is $0.3 \mathrm{~m} / \mathrm{d}$, the specific yield is $\mu=0.02$ according to the empirical value of common rock specific yield, and the water conductivity coefficient of aquifer is $T=k H=9 \mathrm{~m}^{2} / \mathrm{d}$. According to Table 2, the annual average precipitation of Fuzhou is $1359 \mathrm{~mm}$. The lithology of this area is relatively broken, so the rainfall infiltration coefficient is taken as $p=0.2$. The allowable drainage calculation parameters are summarized in Table 3.

4.2. Ecological Groundwater Table. According to the field survey, the main plants above the tunnel are camphor tree, mango tree, longan tree, and banyan tree, among which the diameter of camphor tree is $0.3 \mathrm{~m}-0.9 \mathrm{~m}$, mango tree is $0.3-0.8 \mathrm{~m}$, longan tree is $0.2-0.4 \mathrm{~m}$, and banyan tree is $0.7-1.5 \mathrm{~m}$.

At present, there is no research on ecological groundwater table for these trees. Therefore, when comprehensively considering ecological protection and construction cost, the ecological groundwater table is $5 \mathrm{~m}$ referring to Table 4 [42].

\section{Results and Discussion}

5.1. Time t for the Groundwater Table to Reach the Ecological Balance of Groundwater. According to Section 4.2, the maximum allowable groundwater drawdown in this area is $s=5 \mathrm{~m}$.

According to the geotechnical engineering investigation report of the detailed investigation stage of the extension line project of North Industrial Road (section I) in Fuzhou City [41], the normal water inflow of the left tunnel is $543.77 \mathrm{~m}^{3} / \mathrm{d}$ and the maximum water inflow is $1882.91 \mathrm{~m}^{3} / \mathrm{d}$. The normal water inflow of the right tunnel is $506.20 \mathrm{~m}^{3} / \mathrm{d}$ and the maximum water inflow is $2011.31 \mathrm{~m}^{3} / \mathrm{d}$. Take the average water inflow of a single-hole tunnel $q=1.24 \mathrm{~m}^{3} /(\mathrm{m} \cdot \mathrm{d})$.

Given that $q=1.24 \mathrm{~m}^{3} /(\mathrm{m} \cdot \mathrm{d})$ and allowable drawdown $s=s_{l}+s_{r}=5 \mathrm{~m}$, the time $t$ of drawdown at the center of the left tunnel can be calculated by equations (28) and (29). The relationship between $s$ and time $t$ at the center of the tunnel is obtained through MATLAB programming, as shown in Figure 7. It is obtained that the allowable drawdown reaches $5 \mathrm{~m}$ when $t=9 \mathrm{~d}$ (integer). In other words, when there is no supply, the groundwater table in the center of the left tunnel drops by $5 \mathrm{~m}$ when $t=9 \mathrm{~d}$.

5.2. Configuration and Expansion Form of Groundwater Falling Funnel. For the drawdown $s$ of any point, $s=s_{1}+s_{2}$ is formed by superposition of the drawdown of the left tunnel and right tunnel. Setting $x=0$, the drawdown of groundwater table in the transverse section of the tunnel center can be obtained, as shown in Figure 8.

Setting $y=0$, the drawdown of groundwater table in the longitudinal section of the tunnel center can be obtained, as shown in Figure 9.

In order to more directly observe the trend of groundwater table changing with time, a three-dimensional diagram of drawdown was obtained by MATLAB, as shown in Figure 10.

It can be seen from Figures 8-10 that with the increase of time, the drawdown of groundwater table increases continuously, and the drawdown at the center of the two tunnels is the largest.

5.3. Influence Range Caused by Tunnel Drainage. According to equation (32), when $t=9 \mathrm{~d}$, set $s_{h} \approx 0$. When $s_{h}<0.01 \mathrm{~m}, b=260 \mathrm{~m}$ is obtained, that is, the ellipse short radius of tunnel influence area.

According to equation (35), when $t=9 \mathrm{~d}$, set $s_{z} \approx 0$. When $s_{z}<0.01 \mathrm{~m}, l=720 \mathrm{~m}$ is obtained, that is, the ellipse long radius of tunnel influence area.

Here the precision of $l$ and $b$ is $1 e-2$, which meet the engineering calculation accuracy.

\subsection{Analysis of Groundwater Balance}

5.4.1. Determination of Groundwater Total Discharge. The total discharge of groundwater is determined by equation (38), so we can get $Q_{t}=\left(Q_{1}+Q_{2}\right)=\left(q_{1} L t+q_{2} L t\right)=$ $22320 \mathrm{~m}^{3}$.

5.4.2. Determination of Rainfall Infiltration Recharge. First, the area of precipitation supply area is obtained by equation (36), so we can get $F=\pi l b=588106 \mathrm{~m}^{3}$.

Second, the daily precipitation supply in the influence area can be obtained by equation (37), so we can get $W_{r}=\rho W F / 365=437.71 \mathrm{~m}^{3}$.

Third, the total precipitation supply in $9 \mathrm{~d}$ can be obtained by equation (39), so we can get $W_{t}=W_{r} t=3939 \mathrm{~m}^{3}$.

Fourth, it can be found that $Q_{t}$ is greater than $W_{t}$, which shows that long-term discharge will cause groundwater drying up, so appropriate measures should be taken to reduce groundwater discharge, so as to achieve groundwater balance.

5.5. Determination of Balanced Drainage for Maintaining Groundwater. According to Section 5.4, when the discharge 
TABle 2: Climate data of Fuzhou (in China).

\begin{tabular}{lcccccccccccc}
\hline Name & Jan & Feb & Mar & Apr & May & Jun & Jul & Aug & Sep & Oct & Nov & Dec \\
\hline Average precipitation $(\mathrm{mm})$ & 50 & 82 & 130 & 148 & 201 & 210 & 113 & 165 & 145 & 46 & 37 & 32 \\
\hline
\end{tabular}

TABLE 3: The allowable drainage calculation parameters.

\begin{tabular}{lc}
\hline Parameter type & Parameter value \\
\hline Permeability coefficient of surrounding rock $K(\mathrm{~m} / \mathrm{d})$ & 0.3 \\
Specific yield $\mu$ & 0.02 \\
Aquifer thickness $H(\mathrm{~m})$ & 30 \\
Water conductivity coefficient of aquifer $T\left(\mathrm{~m}^{2} / \mathrm{d}\right)$ & 9 \\
Equivalent circle radius of tunnel cross section $R_{0}(\mathrm{~m})$ & 10.8 \\
Tunnel length passing through the aquifer $L(\mathrm{~m})$ & 1000 \\
Expansion width of tunnel $B(\mathrm{~m})$ & $2 \pi R_{0}=67.86$ \\
Distance between two tunnels $D(\mathrm{~m})$ & 20 \\
Average annual precipitation $W(\mathrm{~mm})$ & 1359 \\
Precipitation infiltration coefficient $p$ & 0.2 \\
\hline
\end{tabular}

TABLE 4: Relationship between groundwater table and vegetation growth.

Kinds of groundwater table

Depth to groundwater $(\mathrm{m})$

Saline buried depth

The best buried depth of groundwater table

Buried depth of groundwater to bear for trees and shrubs

Buried depth of groundwater to warn

$3-5$

Buried depth of groundwater to decline for trees

$5-8$

Buried depth of groundwater to wither for trees

$>12$

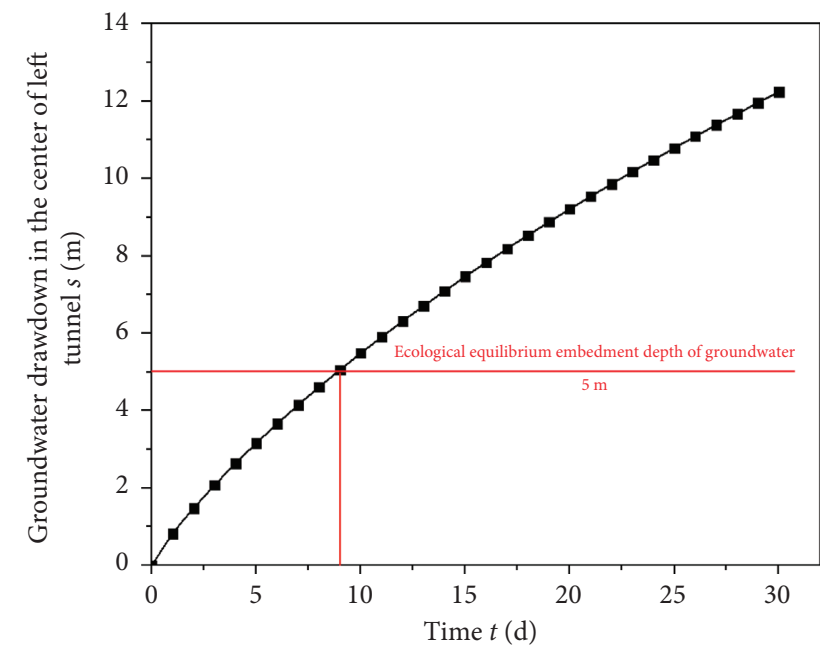

Figure 7: The relationship between groundwater drawdown and time in the center of the left tunnel.

of a single-hole tunnel is $q=1.24 \mathrm{~m}^{3} /(\mathrm{m} \cdot \mathrm{d}), Q_{t}$ is greater than $W_{t}$. Therefore, the value of $q$ needs to be reduced to make $Q_{t}=W_{t}$. Because the range of $q$ cannot be obtained before calculation, and the calculation efficiency will be serious if the range is too large, so the Bisection method is adopted.

Specific steps: (1) first determine the value interval of $q$ $(0,1.24)$ and take the median value of 0.62 in the interval for trial calculation. In this case, $W_{t}-Q_{t}\left(\mathrm{~m}^{3}\right)<0$. (2) Determine the value interval of $q(0,0.62)$ again and take the median

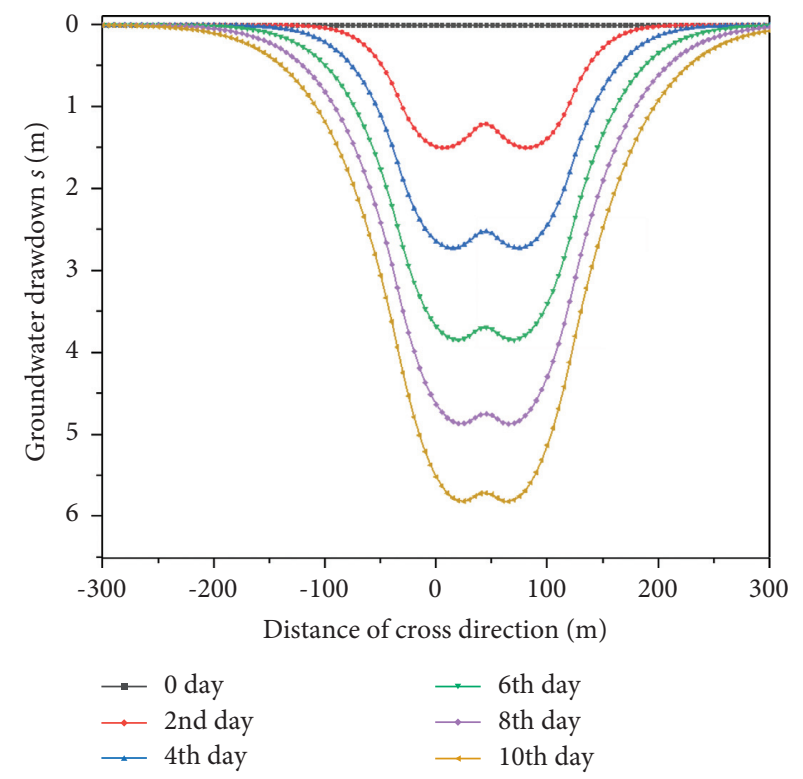

FIGURE 8: Groundwater drawdown in cross section in the tunnel center.

value within the interval 0.31 for trial calculation. In this case, $W_{t}-Q_{t}\left(\mathrm{~m}^{3}\right)>0$. (3) Determine the value interval of $q$ $(0.31,0.62)$ again and take the median value of 0.465 in the interval for trial calculation. In this case, $W_{t}-Q_{t}\left(\mathrm{~m}^{3}\right)>0$. (4) Determine the value range of $q(0.465,0.62)$ again. Since $q=0.465 \mathrm{~m}^{3} /(\mathrm{m} \cdot \mathrm{d}), W_{t}$ is close to $Q_{t}$, so $q=0.48, q=0.49$, 


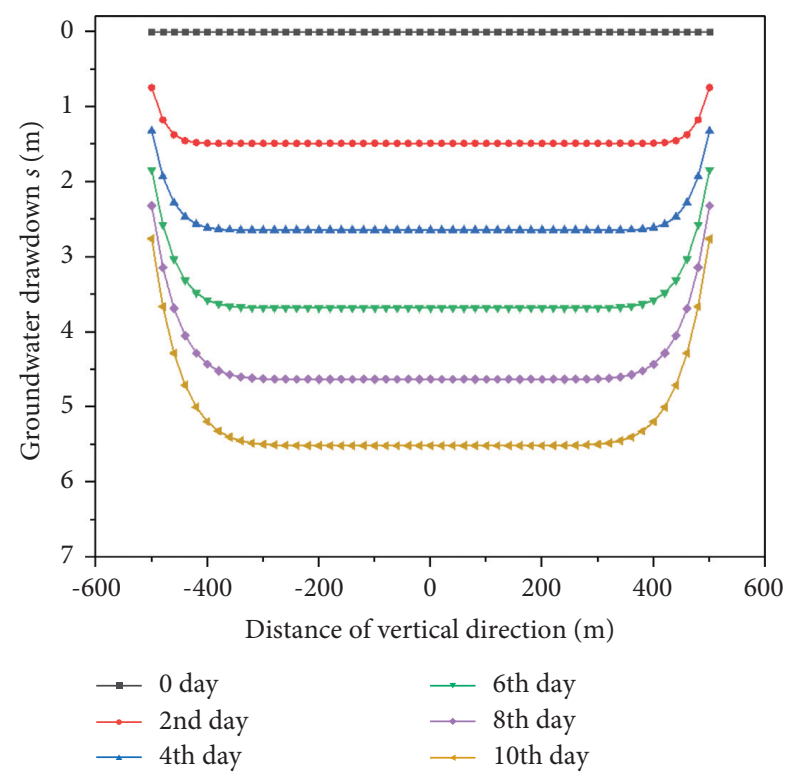

Figure 9: Groundwater drawdown in longitudinal section in the tunnel center.

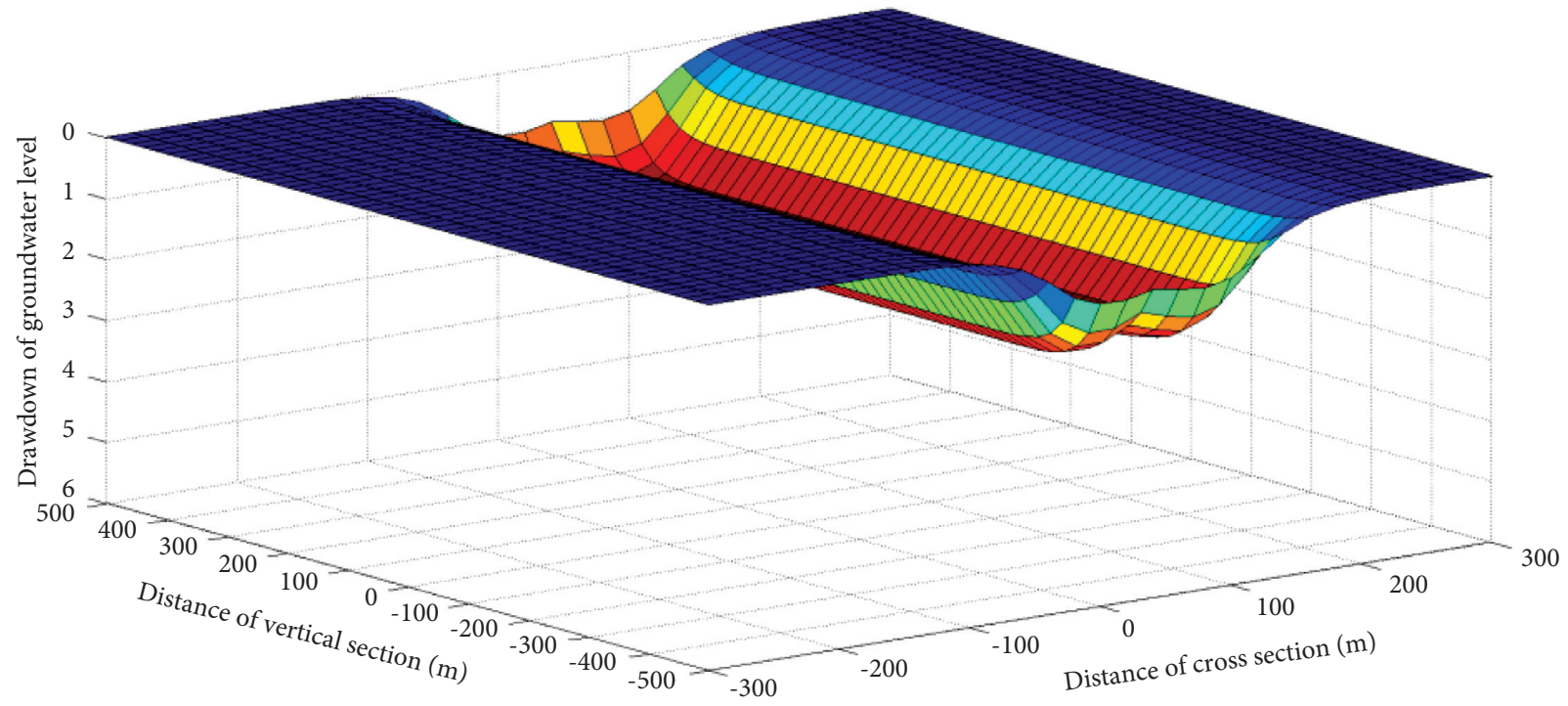

(a)

FIgURE 10: Continued. 


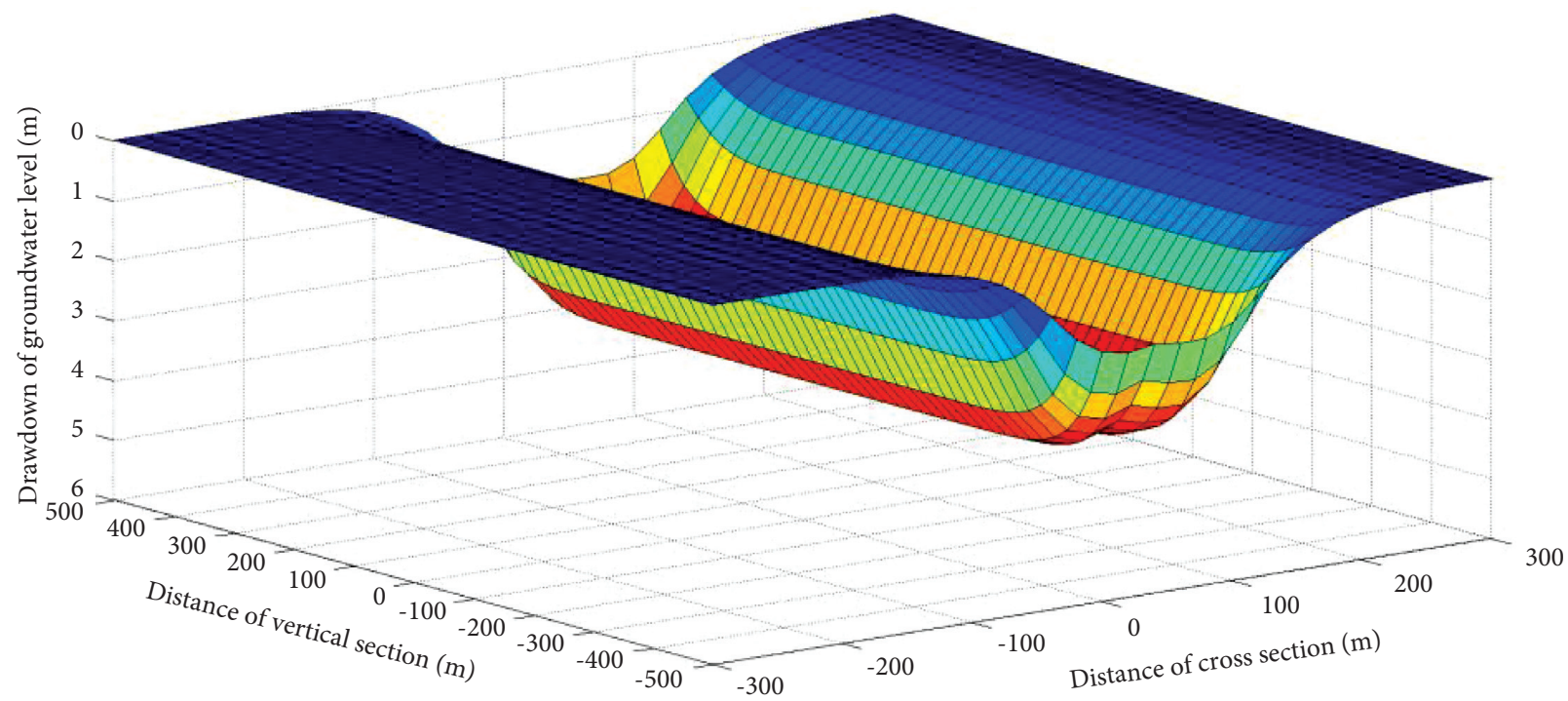

(b)

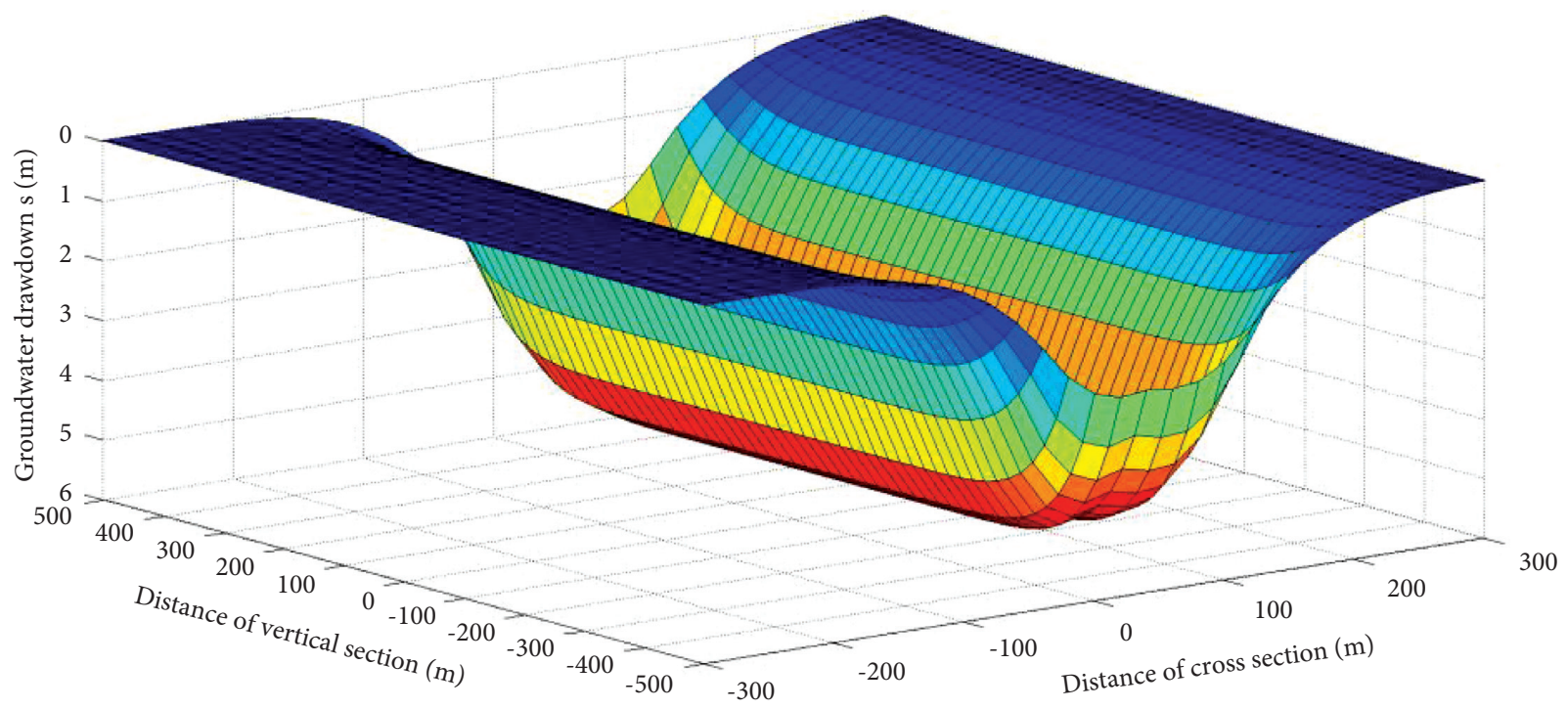

(c)

Figure 10: Three-dimensional diagram of groundwater drawdown: (a) groundwater drawdown on the 3rd day; (b) groundwater drawdown on the 6th day; (c) groundwater drawdown on the 9th day.

TABLe 5: Parameter values under different unit water inflow $q$.

\begin{tabular}{lcccccc}
\hline$q\left(\mathrm{~m}^{3} /(\mathrm{m} \cdot \mathrm{d})\right)$ & $t(\mathrm{~d})$ & $l(\mathrm{~m})$ & $b(\mathrm{~m})$ & $W_{t}\left(\mathrm{~m}^{3}\right)$ & $Q_{t}\left(\mathrm{~m}^{3}\right)$ & $W_{t}-Q_{t}\left(\mathrm{~m}^{3}\right)$ \\
\hline 1.24 & 9 & 720 & 260 & 3939 & 22320 & -18381 \\
0.62 & 23 & 840 & 400 & 18070 & 28520 & -10450 \\
0.50 & 31 & 880 & 465 & 29661 & 31000 & -1339 \\
0.49 & 32 & 885 & 470 & 31123 & 31360 & -237 \\
0.48 & 33 & 890 & 480 & 32963 & 31680 & 1283 \\
0.465 & 34 & 900 & 485 & 34701 & 31620 & 3081 \\
0.31 & 66 & 1060 & 670 & 109600 & 40920 & 68680 \\
\hline
\end{tabular}

and $q=0.50$ are selected for trial calculation. When $q=0.48$, $W_{t}-Q_{t}=1283 \mathrm{~m}^{3}>0 . \quad$ When $q=0.49$, $W_{t}-Q_{t}=-237 \mathrm{~m}^{3}<0$. Table 5 and Figures $11-13$ can be obtained by selecting different $q$ values for trial calculation.
From Figures 11-13, it can be seen that with the increase of unit water inflow $q_{0}$, the time $t$ required to reach a certain drawdown gradually decreases, indicating that the larger the groundwater discharge is, the faster the groundwater table 


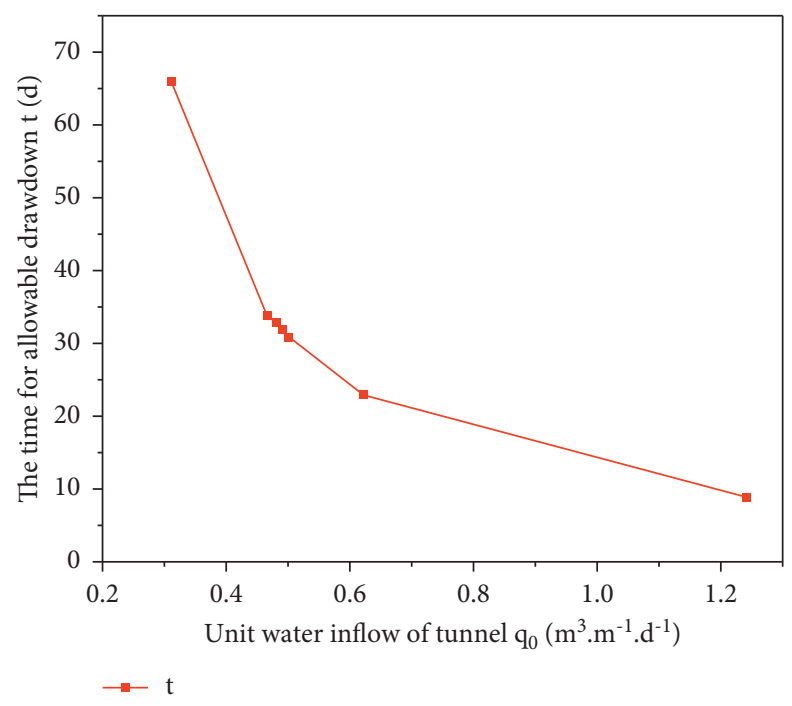

FIGURE 11: The relationship between $q_{0}$ and the time $\mathrm{t}$ reaching the allowable groundwater drawdown.

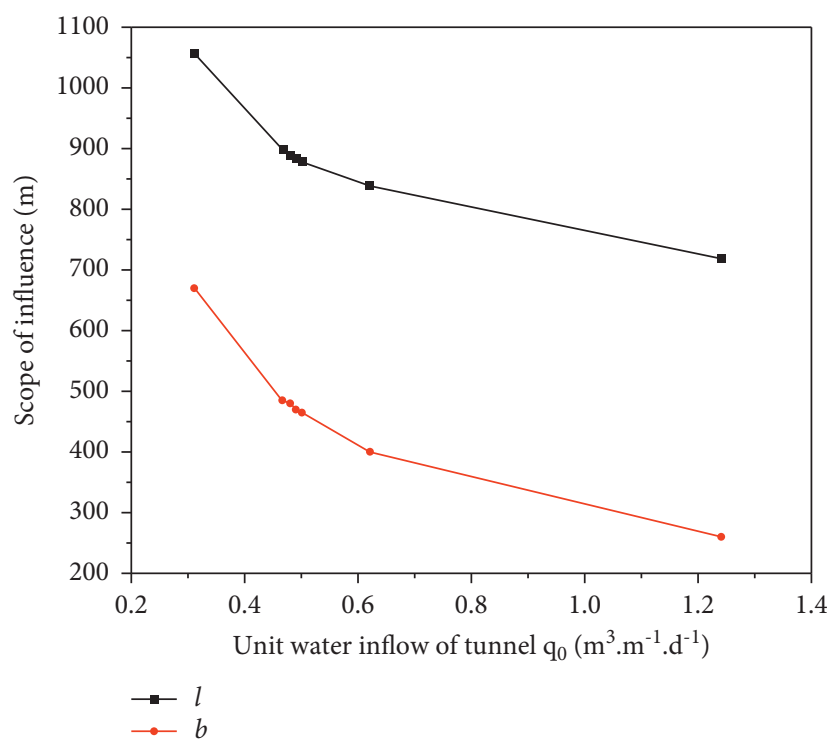

FIGURE 12: The relationship between $q_{0}$ and influence scope.

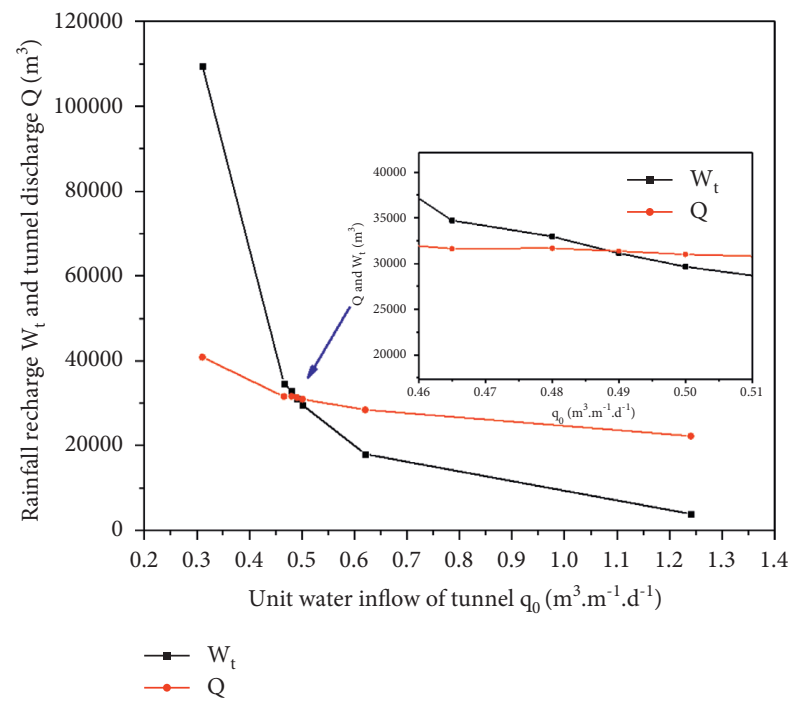

FIGURE 13: The relationship between $q_{0}$ and rainfall recharge $W_{t}$ and tunnel discharge $Q_{t}$. 

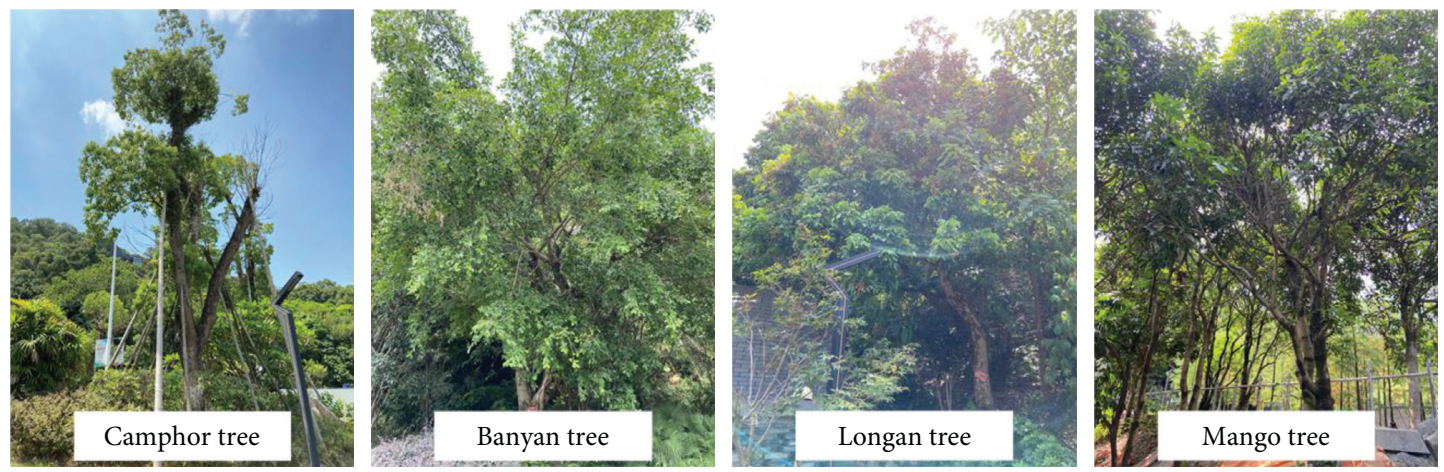

FIGURE 14: Growth of vegetation above the tunnel after operation.

drops. The influence range gradually decreases because the influence range is a function of time $t$, and the decrease of $t$ leads to the decrease of the influence range of tunnel. The total recharge and discharge decrease with the increase of unit water inflow when reaching the established drawdown. It can be seen from Figure 13 that when $q_{0}$ is about $0.48 \mathrm{~m}^{3} /$ $(\mathrm{m} \cdot \mathrm{d})$, the total discharge is equal to the total recharge, and when $q$ is less than $0.48 \mathrm{~m}^{3} /(\mathrm{m} \cdot \mathrm{d})$, the recharge is greater than the discharge, which is beneficial to the groundwater balance, and when $q$ is greater than $0.48 \mathrm{~m}^{3} /(\mathrm{m} \cdot \mathrm{d})$, the total discharge is greater than the recharge, which means that the recharge cannot reach the balance with the discharge, so the unit water inflow $q_{0}=0.48 \mathrm{~m}^{3} /(\mathrm{m} \cdot \mathrm{d})$ is more suitable for discharge.

After one year's operation of the tunnel, the vegetation above the tunnel is growing well (Figure 14), which proves that the calculation method for this limit drainage is reliable.

\section{Conclusion}

By introducing the concept of ecological groundwater table in ecology, based on the method of groundwater dynamics and considering rainfall recharge, this paper analyzes the calculating method of tunnel drainage to maintain groundwater balance and draws the following conclusions:

(1) From the perspective of protecting ecological vegetation from destruction, the relationship between groundwater drawdown and drainage in a singlehole tunnel is deduced based on the area-well method, as shown in equation (19). On that basis, the relationship between groundwater drawdown and drainage of the separated double tunnel is deduced by considering the superposition effect, as shown in equations (24) and (27). The purpose is to control the groundwater drawdown within the range required for the normal growth of vegetation and to maintain the ecological balance of vegetation in the tunnel site.

(2) Based on area-well method, the relationship between the water inflow quantity and groundwater drawdown is obtained. It is also used to calculate the influence scope of the tunnel with a drawdown of approximately $0 \mathrm{~m}$; thus, the area replenished by rainfall infiltration is determined. Based on the rainfall infiltration coefficient, the rainfall infiltration supplement $W_{t}$ is obtained, which is compared with the groundwater discharge $Q_{t}$. By continuously adjusting the unit water inflow $q_{0}$, the total groundwater discharge $Q_{t}$ and the rainfall infiltration supplement $W_{t}$ are equal. When they are equal, the unit water inflow $q_{0}$ can maintain the groundwater balance.

(3) Based on the actual example of a separated double tunnel under construction, the paper puts forward the unit water inflow of the tunnel to keep the groundwater balance, which is $0.48 \mathrm{~m}^{3} /(\mathrm{m} \cdot \mathrm{d})$. In the process of analysis, the two-dimensional and threedimensional diagram of groundwater drawdown with time change are described by MATLAB programming, which gives an intuitive understanding of the shape of groundwater drawdown funnel.

(4) When the groundwater drawdown is constant, the time $t$ and influence range gradually decrease with the increase of unit water inflow $q_{0}$. The total rainfall recharge $W_{t}$ and tunnel discharge $Q_{t}$ also decrease with the increase of unit water inflow $q_{0}$.

\section{Data Availability}

Data are available upon request.

\section{Conflicts of Interest}

The authors declare that there are no conflicts of interest.

\section{Acknowledgments}

This work was financially supported by a grant from the Hebei Provincial Expressway Yanqing-Chongli Construction Office (grant no. YC-201903). In addition, the authors would like to thank the Fuzhou Municipal Construction Development Co., Ltd. (grant no. 20191061), which provided the construction site and geological exploration data.

\section{References}

[1] C. Butscher, P. Huggenberger, and E. Zechner, "Impact of tunneling on regional groundwater flow and implications for 
swelling of clay-sulfate rocks," Engineering Geology, vol. 117, no. 3-4, pp. 198-206, 2011.

[2] D. Ma, H. Duan, X. Li, Z. Li, Z. Zhou, and T. Li, "Effects of seepage-induced erosion on nonlinear hydraulic properties of broken red sandstones," Tunnelling and Underground Space Technology, vol. 91, 2019a.

[3] F. Mossmark, L. O. Ericsson, M. Norin, and L.-O. Dahlström, "Hydrochemical changes caused by underground constructions - a case study of the Kattleberg rail tunnel," Engineering Geology, vol. 191, pp. 86-98, 2015.

[4] E. Pujades, E. Vázquez-Suñé, L. Culí, J. Carrera, A. Ledesma, and A. Jurado, "Hydrogeological impact assessment by tunnelling at sites of high sensitivity," Engineering Geology, vol. 193, pp. 421-434, 2015.

[5] J. R. Raposo, J. Molinero, and J. Dafonte, "Quantitative evaluation of hydrogeological impact produced by tunnel construction using water balance models," Engineering Geology, vol. 116, no. 3-4, pp. 323-332, 2010.

[6] A. Sjölander-Lindqvist, "Conflicting perspectives on water in a Swedish railway tunnel project," Environmental Values, vol. 14, no. 2, pp. 221-239, 2005.

[7] T. Strozzi, R. Caduff, U. Wegmüller, H. Raetzo, and M. Hauser, "Widespread surface subsidence induced in Alpine hard rocks by the construction of the 57 kilometres-long Gotthard Base Tunnel (Switzerland) observed with satellite SAR interferometry," Procedia Technology, vol. 16, pp. 69-73, 2014.

[8] V. Vincenzi, A. Gargini, and N. Goldscheider, "Using tracer tests and hydrological observations to evaluate effects of tunnel drainage on groundwater and surface waters in the Northern Apennines (Italy)," Hydrogeology Journal, vol. 17, no. 1, pp. 135-150, 2009.

[9] Q. Xie, S. Dan, and W. Yang, "Evaluation of groundwater environmental disturbance by mountain highway tunnel construction," Geological Journal of China Universities, vol. 25, no. 3, pp. 437-443, 2019.

[10] K. Su, Y. Zhou, H. Wu, C. Shi, and L. Zhou, “An analytical method for groundwater inflow into a drained circular tunnel," Groundwater, vol. 55, no. 5, pp. 712-721, 2017.

[11] C. Yoo, "Interaction between tunneling and groundwaternumerical investigation using three dimensional stress-pore pressure coupled analysis," Journal of Geotechnical and Geoenvironmental Engineering, vol. 131, no. 2, pp. 240-250, 2005.

[12] G. T. Chae, S. T. Yun, B. Y. Choi et al., "Hydrochemistry of urban groundwater, Seoul, Korea: the impact of subway tunnels on groundwater quality," Journal of Contaminant Hydrology, vol. 101, no. 1-4, pp. 42-52, 2008.

[13] J. Luo and W. Fu, "Destruction caused by tunneling works to the circulatory system of underground water in karst areas - a case study of the Zhongliang mountains in Chongqing," Journal of Southwest Agricultural University, vol. 27, no. 4, pp. 432-435, 2005.

[14] P. Cheng, L. Zhao, Z. Luo et al., "Analytical solution for the limiting drainage of a mountain tunnel based on area-well theory," Tunnelling and Underground Space Technology, vol. 84, pp. 22-30, 2019.

[15] W. Zheng, X. Wang, Y. Tang, H. Liu, M. Wang, and L. Zhang, "Use of tree rings as indicator for groundwater level drawdown caused by tunnel excavation in Zhongliang Mountains, Chongqing, Southwest China," Environmental Earth Sciences, vol. 76, no. 15, p. 522, 2017.

[16] F. Wang, W. Zheng, H. Xu, and J. Chen, "Influence of groundwater loss induced by karst tunnel construction on growth of surrounding vegetation and its countermeasures," Tunnel Construction, vol. 38, no. 6, pp. 915-923, 2018.

[17] J. Liu, L. Shen, Z. Wang et al., "Response of plants water uptake patterns to tunnels excavation based on stable isotopes in a karst trough valley," Journal Of Hydrology, vol. 571, pp. 485-493, 2019.

[18] P. Arjnoi, J.-H. Jeong, C.-Y. Kim, and K.-H. Park, "Effect of drainage conditions on porewater pressure distributions and lining stresses in drained tunnels," Tunnelling and Underground Space Technology, vol. 24, no. 4, pp. 376-389, 2009.

[19] X. Wang, z. Tan, M. Wang, M. Zhang, and H. Ming, "Theoretical and experimental study of external water pressure on tunnel lining in controlled drainage under high water level," Tunnelling and Underground Space Technology, vol. 23, no. 5, pp. 552-560, 2008.

[20] G. Xu, C. He, C. Qi, Z. Zhang, and C. Dai, "Study on Water Pressure Distribution and Inner Force of Drainaged Segment Lining," in Proceedings of the ICPTT 2012: Better Pipeline Infrastructure for a Better Life, pp. 1502-1511, Wuhan, China, October 2013.

[21] C. Zhang, D. Zhang, M. Wang, and Y. Xiang, "Study on appropriate parameters of grouting circle for tunnels with limiting discharge lining in high water pressure and waterenriched region Chinese," Journal of Rock Mechanics and Engineering, vol. 26, no. 11, pp. 2270-2276, 2007.

[22] M.-Q. Zhang and H.-J. Huang, "Technology for blocking water by grouting for high-pressure cranny water of qiyueshan tunnel," Journal of Railway Engineering Society, vol. 136, no. 1, pp. 68-73, 2010.

[23] Z. Zou, "Application of waterproof technology by curtain grouting to Geleshan Tunnel construction," Modern Tunnelling Technology, vol. 40, no. 1, pp. 44-49, 2003.

[24] O. Blindheim and E. Ovstedal, "Design Principles and Construction Methods for Water Control in Subsea Road Tunnels in rock," Water Control in Norwegian Tunnelling, vol. 12, 2002.

[25] E. Grov, "Water Control in Norwegian Tunnelling," in Proceedings of the AITES-ITA Downunder 2002: 28th ITA General Assembly and World Tunnel Congress, p. 656, March 2002, Modern Tunnels-Challenges and Solutions.

[26] N. Li, Study of the Impact on the Water Environment during the Construction of the Geleshan Railway Tunnel, Southwest Jiaotong University, Chengdu, China, 2004.

[27] P. Cheng, L.-h. Zhao, L. Li, J.-f. Zou, and W. Luo, "Limiting drainage criterion for groundwater of mountain tunnel," Journal of Central South University, vol. 21, no. 12, pp. 4660-4668, 2014.

[28] D. Ma, H. Duan, J. Liu, X. Li, and Z. Zhou, "The role of gangue on the mitigation of mining-induced hazards and environmental pollution: an experimental investigation," The Science of the Total Environment, vol. 664, pp. 436-448, 2019.

[29] D. Ma, J. Zhang, H. Duan et al., "Reutilization of gangue wastes in underground backfilling mining: overburden aquifer protection," Chemosphere, vol. 264, no. 1, Article ID 128400, 2021.

[30] H. Zhang, "The ecological equilibrium embedment depth of groundwater in arid region," Site Investigation Science and Technology, vol. 6, no. 20, pp. 9-13, 1992.

[31] Z. Yang, W. Li, X. Li, and J. He, "Quantitative analysis of the relationship between vegetation and groundwater buried depth: a case study of a coal mine district in Western China," Ecological Indicators, vol. 102, pp. 770-782, 2019.

[32] S. Liu, W. Li, W. Qiao, Q. Wang, Y. Hu, and Z. Wang, "Effect of natural conditions and mining activities on vegetation 
variations in arid and semiarid mining regions," Ecological Indicators, vol. 103, pp. 331-345, 2019.

[33] J. L. Horton, T. E. Kolb, and S. C. Hart, "Physiological response to groundwater depth varies among species and with river flow regulation," Ecological Applications, vol. 11, no. 4, pp. 1046-1059, 2001.

[34] B. D. Newman, B. P. Wilcox, S. R. Archer et al., "Ecohydrology of water-limited environments: a scientific vision," Water Resources Research, vol. 42, no. 6, 2006.

[35] R. Shi, X. Li, X. Dong, P.-n. Yang, and L. Liu, "Research on the relationship between natural vegetation growth and groundwater in Yanqi basin," Journal of Natural Resources, vol. 24, no. 12, pp. 2096-2103, 2009.

[36] D.-H. Cheng, W.-K. Wang, G.-C. Hou, H.-B. Yang, Y. Li, and E.-Y. Zhang, "Relationship between vegetation and groundwater in $\mathrm{Mu}$ Us desert," Journal of Jilin University(Earth Science Edition), vol. 42, no. 1, pp. 184-189, 2012.

[37] C. Chen and M. Lin, Groundwater Dynamics, China University of Geosciences Press, Wuhan, China, 1998.

[38] C. V. Theis, "The relation between the lowering of the piezometric surface and the rate and duration of discharge of a well using ground-water storage," Transactions - American Geophysical Union, vol. 16, no. 2, pp. 519-524, 1935.

[39] R. Zhang, X. Liang, M. Jin, L. Wan, and Q. Yu, Fundamentals of Hydrogeology, Geological Publishing House, Beijing, China, 2011.

[40] D. Zhu and Q. Li, "Predication of outflow in tunnel based on experimental permeating coefficient of precipitation," Journal of Railway Engineering Society, vol. 45, no. 1, pp. 100-102, 1995.

[41] Z. Xiao and J. Zhang, The Geotechnical Engineering Investigation Report of the Detailed Investigation Stage of the Extension Line Project of North Industrial Road (Section I) in Fuzhou City, Fuzhou Investigation and Surveying Institute, Fuzhou, China, 2018.

[42] S. Wang, Q. Huang, L. Fan, and W. Wang, Coal Mining and Ecological Water Level protection in Ecologically Fragile Areas, Science China Press, Beijing, China, 2010. 